\title{
Implementation challenges and perception of care providers on Electronic Medical Records at St. Paul's and Ayder Hospitals, Ethiopia
}

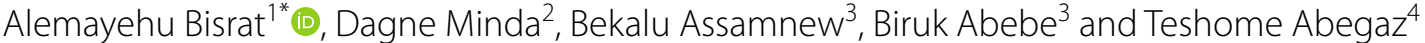

\begin{abstract}
Background: In resources constrained settings, effectively implemented Electronic Medical Record systems have numerous benefits over paper-based record keeping. This system was implemented in the 2009 Gregorian Calendar in the two Ethiopian territory hospitals, Ayder and St. Paul's. The pilot implementation and similar re-deployment efforts done in 2014 and 2017 Gregorian Calendar failed at St. Paul's. This study aimed to assess the current status, identify challenges, success factors and perception of health care providers to the system to inform on future roll-outs and scale-up plans.

Methods: A cross sectional study design with quantitative and qualitative methods was employed. A survey was administered October to December 2019 using a structured questionnaire. A total of 240 health care providers participated in the study based on a stratified random sampling technique. An interview was conducted with a total of 10 persons that include IT experts and higher managements of the hospital. Descriptive statistics were employed to summarize the survey data using SPSS V.21. Qualitative data were thematically presented.
\end{abstract}

Results: St. Paul's hospital predominantly practiced the manual medical recording system. The majority of respondents (30.6\%) declared that a lack of training and follow up, lack of management commitment, poor network infrastructure and hardware/software-related issues were challenges and contributed to EMR system failure at St. Paul's. Results from the qualitative data attested to the above results. The system is found well-functioning at Ayder, and the majority of respondents (38\%) noted that lack of training and follow-up was the most piercing challenge. As per the qualitative findings, ICT infrastructure, availability of equipment, incentive mechanisms, and management commitment are mentioned as supportive for successful implementation. At both hospitals, 70 to $95 \%$ of participants hold favorable perceptions and are willing to use the system.

Conclusion: Assessing the readiness of the hospital, selecting and acquiring standard and certified EMR systems, provision of adequate logistic requirements including equipment and supplies, and upgrading the hospital ICT infrastructure will allow sustainable deployment of an EMR system.

Keywords: Electronic Medical Record, Medical record, EMR implementation, Ethiopia

*Correspondence: alemayehu.bisrat@sphmmc.edu.et

${ }^{1}$ Library and Info Service Directorate, St. Paul's Hospital Millennium

Medical College, PO Box 1271, Addis Ababa, Ethiopia

Full list of author information is available at the end of the article

\begin{abstract}
Background
Information technology has transformed nearly every single side of our lives. Over the past two decades, particularly in the healthcare system, it has been seen as a key and first step for improving the quality of health care service and patient safety [1]. Health information
\end{abstract}

(c) The Author(s) 2021. Open Access This article is licensed under a Creative Commons Attribution 4.0 International License, which permits use, sharing, adaptation, distribution and reproduction in any medium or format, as long as you give appropriate credit to the original author(s) and the source, provide a link to the Creative Commons licence, and indicate if changes were made. The images or other third party material in this article are included in the article's Creative Commons licence, unless indicated otherwise in a credit line to the material. If material is not included in the article's Creative Commons licence and your intended use is not permitted by statutory regulation or exceeds the permitted use, you will need to obtain permission directly from the copyright holder. To view a copy of this licence, visit http//creativecommons.org/licenses/by/4.0/. The Creative Commons Public Domain Dedication waiver (http://creativecommons.org/publicdomain/zero/1.0/) applies to the data made available in this article, unless otherwise stated in a credit line to the data. 
technology (HIT) has defined as "the application of information processing involving both computer hardware and software that deals with the storage, retrieval, sharing, and use of health care information, data, and knowledge for communication and decision making" [2]. These technologies have been promoted as potential tools for improving quality, reducing cost, and improving the efficiency of the health care system [2]. Studies revealed that HIT offered several opportunities for improving and changing health care. These include; reducing human errors, improving medication safety, improving clinical outcomes, facilitating care coordination, improving practice efficiencies, increasing patient satisfaction, and tracking data over time $[1,3]$.

Among the commonly used health information technology tools intended to improve practice efficiency and patient care, one is Electronic Medical Record. WHO [4] described EMR as a digital version of all the information typically found in a provider's paper chart: medical history, diagnoses, medications, immunization dates, allergies, lab results and doctor's notes [4]. Other studies described EMR as an individual health related information within one health care organization and an essential component of a robust and efficient modern healthcare system $[5,6]$.

Studies identified several reasons for the need of adopting EMR in hospital settings. EMR systems would help achieve improved patient care in terms of safety, efficiency, and quality [1]. It was noted that adopting and implementing EMR can allow easy access to patient information, reduce error, improved quality of care, improved documentation, save time, and improve order and receipt of lab tests as well as diagnostic images [5, $7,8]$. On the other hand, EMR systems facilitate the management of appointments, scheduling, registration, admission, discharge, and transfer of patients [9].

Paper-based hospital record-keeping and workflows dependent on paper have proven to become more and more inefficient and are continuously failing to meet the care providers and patient needs. Paper records were criticized for their limited accessibility and their general incompleteness $[8,10]$. Paper-based systems are considered a human resource and time-intensive and are often plagued by inaccurate reporting processes leading to out-of-date and irrelevant data [11]. Other studies were concluding that patient data in paper records often are vague, ambiguous, incomplete, or hard to extract information from its illegible handwritten pages, has limited opportunities for reuse and sharing of data [10-12].

In spite of some implementation challenges that lead to the failure of pilot projects, EMR systems have been shown to be feasible and documenting numerous benefits, such as medical error prevention, reduction of unnecessary care costs, and hold the greatest promise for improving the quality of health care services. Several studies noted, EMR systems enhance the quality of care, improve communication, decrease patient waiting time, are able to check for drug allergies, calculate doses and help to reduce medical errors $[6,10,13,14]$.

Other studies identified barriers hampering the implementation of EMR in low and middle-income countries. These include limited funding, lack of full-time IT experts, poor information technology infrastructure, lack of automatic data and power backups, and a need to modify the existing workflow processes $[3,15,16]$. Similarly, an EMR deployment requires the availability of appropriate information systems infrastructures, such as reliable power, connectivity, and networking capabilities [9]. Human barriers, including negative beliefs, behaviors, and attitudes of healthcare professionals towards such systems, were mentioned as the most prevalent barriers [17]. Lack of technical expertise, funding, an integrated EMR system, and physicians' time also has been identified as barriers obstructing EMR implementation $[11,18]$.

Despite the concerns and interest in adopting and implementing Electronic Medical Records in our country, there is a large gap between planning to use this system in hospitals and operating them ideally to achieve its purpose and expected benefits. The Federal Ministry of Health has begun the adoption of SmartCare since the 2009 Gregorian Calendar. SmartCare was later renamed Tena Care and became a comprehensive EMR system. The US Centers for Disease Control and Prevention (CDC) initially, developed the system and later on customized and maintained by IT staff and medical doctors of the Tulane University Technical Assistance Project in Ethiopia (TUTAPE). The deployment took place at Ayder and St. Paul's hospitals in the 2009 Gregorian Calendar. While following unsuccessful implementation efforts, consecutive redeployment took place at St. Paul's in 2014 and 2017 Gregorian Calendar. The overall objectives of implementing an EMR in these hospitals were to make health information accessible at the point of service and improve information use, avoid duplicate medical records for a single patient, minimize the shelves used by paper medical records, increase the quality of care delivery and finally save hospital costs. Unfortunately, pieces of evidence on EMR implementation challenges, factors contributing to the success or failure were not found, and evaluation of the systems capability and quality is also meager.

This study aimed to assess the status of the EMR system, identify challenges, facilitators and barriers, while at the same time examine the perception of health care providers toward the system comparing Ayder and St. Paul's 
teaching hospitals to draw a lesson for sustainable EMR deployment at local settings.

The study addressed questions related to what significant contributions did the system brought in health service delivery concerning the two hospitals' performance? What are the success factors, challenges, or impediments, and how do health care providers perceived EMR implementation?

\section{Methods}

\section{Location and settings of the study}

The study was carried out at the biggest referral hospitals in the country where a high volume of patients attends emergency and outpatient clinics daily for advanced medical care and treatment. These are St. Paul's hospital, Addis Ababa, and Ayder hospital, Mekele, where an EMR system was implemented, with the support of the $\mathrm{FMoH}$ and the regional health bureau.

St. Paul's hospital was established in 1968 Gregorian Calendar by the late Emperor Haile Selassie and reorganized as St Paul's Hospital Millennium Medical College through a decree of the Council of Ministers in 2010 Gregorian Calendar, though the medical school opened in 2007 Gregorian calendar. It is governed by a board, under the Federal Ministry of Health.

It has more than 2800 clinical, academic and administrative support staff that provide medical specialty services to patients referred from all over the country, teaching medicine and nursing students and doing basic and applied researches. While the inpatient capacity is more than 700 beds, the hospital sees an average of 1200 emergency and outpatient clients daily.

Ayder Comprehensive Specialized Hospital commenced rendering its referral and non-referral services in 2008 Gregorian Calendar to the 9 million population in its catchment areas of the Tigray, Afar, and North-eastern parts of the Amhara Regional States including the Eritrean refugees.

The hospital can be designated as the most advanced medical facility by all accounts in the Northern part of the country, and it stands as the second-largest hospital in the nation with a total capacity of about 500 inpatient beds in all departments and other specialty units. It is used as a teaching hospital and research center for the College of Health Sciences, Mekelle University. It has above 80 specialists, in various areas of medical specializations and fairly adequate numbers of all the other health professionals constituting the health care team.

\section{Survey design}

The study design used both quantitative and qualitative approaches. The survey employed a structured and selfcompletion questionnaire. It used a stratified random sampling technique. For the qualitative part of the study, a purposive sampling technique was applied to interview key informants such as IT staff, EMR system administrators, medical directors, and hospital provosts.

\section{Data sources}

The study was limited to respondents serving in St. Paul's Hospital Millennium Medical College and Ayder referral hospital. The study population covers Specialists, General Practitioners, Nurses, Laboratory Scientists and Pharmacists working full time in both St. Paul's i.e. 1400, and Ayder hospitals i.e. 1000 that totals 2400. Besides, an in-depth interview with key informants that include 3 IT staff working in relation to EMR systems and 2 staff from the senior managements from each hospital was conducted.

\section{Sample size}

The sample size of 100 and 140 from Ayder and St. Paul's respectively representing approximately $10 \%$ of the study population was selected using a table of random figures. The total sample size was 240 .

The formula for calculating the sample size was:

$$
\mathrm{nr}=\frac{4 \mathrm{pq}}{\mathrm{d}^{2}}
$$

where $\mathrm{nr}=$ required sample size, $\mathrm{p}=$ proportion of the population having the characteristic, $q=1-p$ and $d=$ the degree of precision (for this case a 10\% margin of error i.e. $d=0.1$.

\section{Data collection procedure}

A structured and pre-validated questionnaire was used which contained sections on Socio-Demographics; Knowledge, Perceived Benefits and Usefulness; and Perception and Willingness (Additional file 1).

The perception was assessed using 5 perception items measured by a five-point Likert scale 'Strongly Disagree $=1$ ', 'Disagree =2', Don't Know =3', 'Agree =4' and 'Strongly Agree $=5$ '. Higher scores i.e. 4 and 5 represented a more positive perception towards EMR and willingness to use the system.

The questionnaire was pre-tested before the actual study, on a hospital outside of the study area, and adjusted and proved for its consistency and reliability. The survey was administered October through December 2019 with the help of 2 data collectors and supervised by the investigators. To support the data obtained from the questionnaire with a more detailed story on the system an interview was conducted with key informants including the IT staff, EMR system administrators, higher hospital management with the help of a pre-distributed interview guide (Additional file 1). To ensure the 
trustworthiness of the findings, we tried to use triangulation that showed its credibility. We also tried to control the researcher's bias or personal motivation not to alter the interpretation. The research process and data analysis were reviewed and examined to ensure the findings are

Table 1 Socio-demographic characterstics of respondents by institution

\begin{tabular}{|c|c|c|c|c|}
\hline \multirow[t]{3}{*}{ Item } & \multicolumn{4}{|c|}{ Respondents Institution } \\
\hline & \multicolumn{2}{|c|}{ St. Paul's Hospital } & \multicolumn{2}{|c|}{ Ayder Hospital } \\
\hline & Freq & $\%$ & Freq & $\%$ \\
\hline \multicolumn{5}{|l|}{ Sex } \\
\hline Male & 40 & $55.6 \%$ & 35 & $35.0 \%$ \\
\hline Female & 32 & $44.4 \%$ & 65 & $65.0 \%$ \\
\hline \multicolumn{5}{|l|}{ Age range } \\
\hline $21-30$ & 35 & $48.6 \%$ & 57 & $57.0 \%$ \\
\hline $31-40$ & 25 & $34.7 \%$ & 35 & $35.0 \%$ \\
\hline $41-50$ & 6 & $8.3 \%$ & 7 & $7.0 \%$ \\
\hline $51-60$ & 6 & $8.3 \%$ & 1 & $1.0 \%$ \\
\hline \multicolumn{5}{|c|}{ Professional category } \\
\hline GP & 8 & $11.1 \%$ & 3 & $3.0 \%$ \\
\hline Specialist & 21 & $29.2 \%$ & 10 & $10.0 \%$ \\
\hline Nurse & 36 & $50.0 \%$ & 70 & $70.0 \%$ \\
\hline Lab technician & 3 & $4.2 \%$ & 7 & $7.0 \%$ \\
\hline Pharmacist & 4 & $5.6 \%$ & 10 & $10.0 \%$ \\
\hline \multicolumn{5}{|l|}{ Service year } \\
\hline $1-5$ & 33 & $45.8 \%$ & 32 & $32.0 \%$ \\
\hline $6-10$ & 23 & $31.9 \%$ & 44 & $44.0 \%$ \\
\hline $11-15$ & 10 & $13.9 \%$ & 16 & $16.0 \%$ \\
\hline$>15$ & 6 & $8.3 \%$ & 8 & $8.0 \%$ \\
\hline
\end{tabular}

consistent and could be repeated. Descriptive statistics and chi-square tests were employed to summarize the data and explored associations between variables using SPSS V.21. Results from the qualitative data were categorized and presented.

\section{Results}

A total of 172 participants (100 from Ayder and 72 from St. Paul's), out of 240 health care providers selected for the study, were responded to the survey that made a response rate of $71.7 \%$. Among the study participants, $56.4 \%$ were female, and $43.6 \%$ were male (Table 1 ). It was found that $53.5 \%$ of participants were in the age group of $21-30$ years, while $34.9 \%$ were in the age group of 31-40 years old. Sixty-Seven (39\%) of them have served for 6-10 years, and sixty-five (37.8\%) have 1-5 years of service. Among the participants, $6.4 \%$ were General Practitioners, $18 \%$ were Specialist, $61.6 \%$ were Nurses, $5.8 \%$ were Lab Technicians or laboratory scientists, and $8.1 \%$ were Pharmacists. The majority of the respondents were nurses, which were 50\% at St. Paul's and 70\% at Ayder, followed by specialists, which were $29.2 \%$ at St. Paul's and $10 \%$ at Ayder.

For a question assessing their earlier training attendance on the system, 75\% of St. Paul's and 59\% of Ayder respondents were not attended past EMR system training (Fig. 1). Regarding their know-how of the EMR system, $44.4 \%$ of St. Paul's and $45 \%$ of Ayder respondents knew a few things about the system (Fig. 1).

A chi-square test was employed to test the existence of a relationship between professional categories vis-avis respondents' knowhow of the EMR system (Table 2),

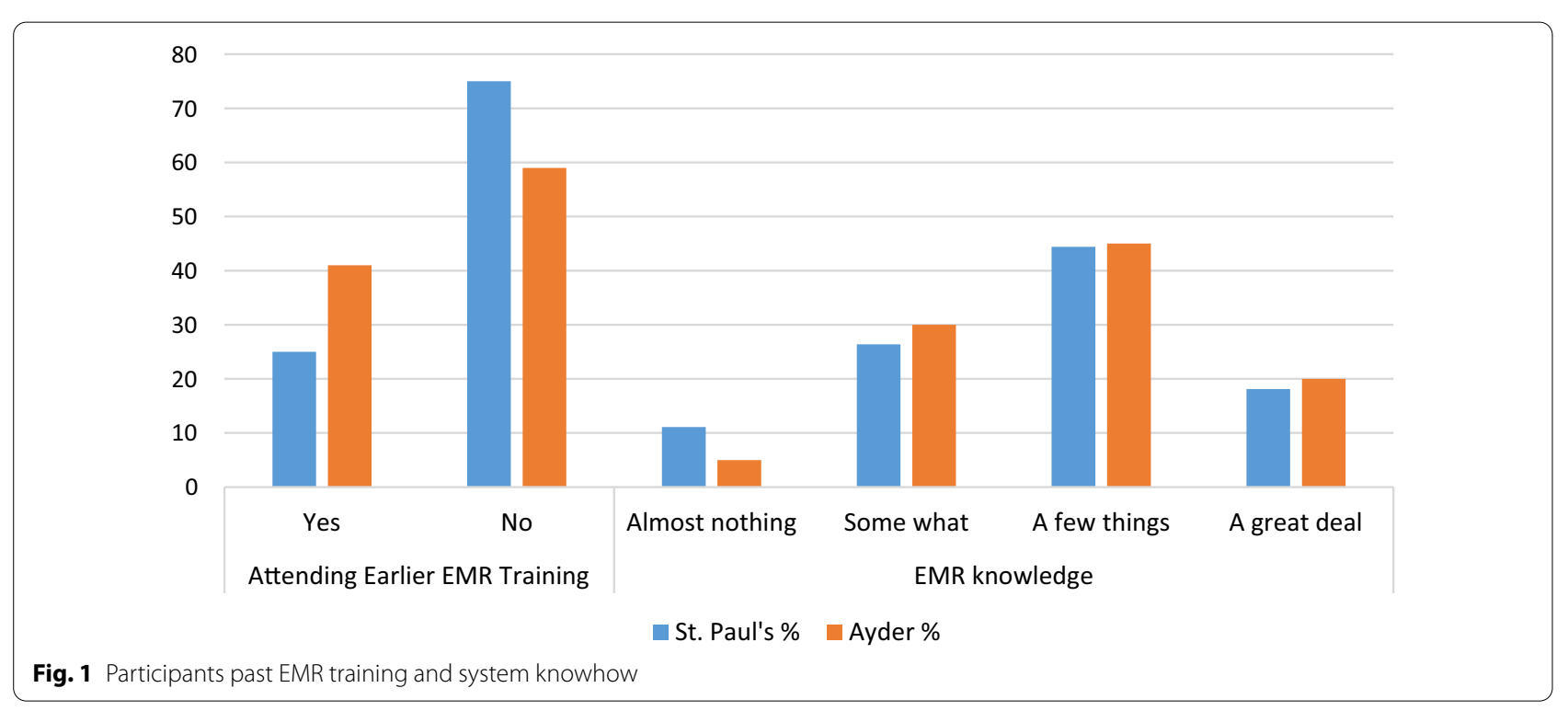


Table 2 Chi-square test of respondent's professional category and know-how of the EMR system

\begin{tabular}{llll}
\hline Test & Value & $\boldsymbol{d f}$ & $\begin{array}{l}\text { Asymp. } \\
\text { Sig. } \\
\text { (2-sided) }\end{array}$ \\
\hline Pearson Chi-square & $14.668^{\mathrm{a}}$ & 12 & .260 \\
Likelihood ratio & 18.458 & 12 & .102 \\
Linear-by-linear association & .581 & 1 & .446 \\
N of valid cases & 172 & & \\
\hline
\end{tabular}

Table 3 Views of respondents on the benefit of the EMR system

\begin{tabular}{|c|c|c|c|c|}
\hline \multirow[t]{3}{*}{ Items } & \multicolumn{4}{|c|}{ Respondents Hospital } \\
\hline & \multicolumn{2}{|c|}{ St. Paul's } & \multicolumn{2}{|c|}{ Ayder } \\
\hline & Freq & $\%$ & Freq & $\%$ \\
\hline \multicolumn{5}{|c|}{ EMR will change /already changed the process of patient care? } \\
\hline Significantly & 61 & $84.7 \%$ & 62 & $62.0 \%$ \\
\hline Small degree & 7 & $9.7 \%$ & 25 & $25.0 \%$ \\
\hline Not at all & 4 & $5.6 \%$ & 13 & $13.0 \%$ \\
\hline \multicolumn{5}{|c|}{ EMR will change/already changed the quality of care? } \\
\hline Will Improve & 67 & $93.1 \%$ & 84 & $84.0 \%$ \\
\hline Decrease & 0 & $0.0 \%$ & 9 & $9.0 \%$ \\
\hline No change & 5 & $6.9 \%$ & 7 & $7.0 \%$ \\
\hline \multicolumn{5}{|c|}{ EMR has a benefit of increasing practice productivity } \\
\hline Yes & 60 & $83.3 \%$ & 85 & $85.0 \%$ \\
\hline No & 12 & $16.7 \%$ & 15 & $15.0 \%$ \\
\hline \multicolumn{5}{|c|}{$\begin{array}{l}\text { EMR has a benefit of decreasing the work load and enhancing effi- } \\
\text { ciency of providers }\end{array}$} \\
\hline Yes & 60 & $83.3 \%$ & 78 & $78.0 \%$ \\
\hline No & 12 & $16.7 \%$ & 22 & $22.0 \%$ \\
\hline \multicolumn{5}{|c|}{$\begin{array}{l}\text { EMR system is safe and secured as compared to a paper based medical } \\
\text { record system }\end{array}$} \\
\hline Yes & 63 & $87.5 \%$ & 86 & $86.0 \%$ \\
\hline No & 9 & $12.5 \%$ & 14 & $14.0 \%$ \\
\hline
\end{tabular}

mean-while, the tests indicated that there was no significant association between the variables.

Findings showed the majority of respondents from St. Paul's viewed using the EMR system as a potential to change the process of patient care significantly (84.7\%), and for $62 \%$ of respondents from Ayder the EMR already significantly changed the process of patient care (Table 3). The system has the potential to improve the quality of care for $93.1 \%$ of St. Paul's respondents, and $84 \%$ of Ayder respondents reported that EMR already improved the quality of care. Further, sixty $(83.3 \%)$ of St. Paul's and Eighty-five (85\%) of Ayder respondents agreed it has a benefit of increasing practice productivity (patient per day). For $83.3 \%$ of St. Paul's and $78 \%$ of Ayder respondents' EMR has the benefit of decreasing workload and enhancing the efficiency of care providers. As per the finding, sixty-three (87.5\%) of St. Paul's and eighty-six (86\%) of Ayder participants responded that patient records available on EMR systems are safer and more secure than paper-based medical recording systems.

Respondents identified barriers and success factors to the implementation of an EMR system. For 29.2\% of St. Paul's respondents suggested barriers were low user acceptance, poor project management, poor ICT infrastructure, and lack of training and follow-up while for $38 \%$ of Ayder respondents lack of training and followup were major challenges to the system implementation (Fig. 2). Furthermore, 21\% of Ayder respondents suggested that poor ICT infrastructure and lack of training and follow-up were barriers to system implementation, while $15.3 \%$ of St. Paul's respondents suggested lack of training and follow-up as barriers. On the other hand, 44.4\% of Ayder and 32\% of St. Paul's respondents suggested commitment and involvement of all medical staff together with good organizational change management, an interdisciplinary team having IT experience, training and incentive mechanisms would result in successful implementation (Fig. 3).

Based on their actual day-to-day clinical practice $88 \%$ of Ayder respondents believed service turnaround time improved or decreased by using the EMR system, and $75 \%$ of the respondents assumed the improvement had ranging from thirty minutes to an hour (Table 4). Assessing EMR system downtime effect on clinical practices, $80 \%$ of Ayder respondents agreed it had a high to serious effect on their clinical practice. Regarding system effect on patients waiting time, $67 \%$ of Ayder respondents noticed a reduction in patient waiting time.

In general, the assessment of the perception of participating health care providers showed positive insights. In both hospitals, findings of the study on perception towards the system indicated favorable perception, particularly on the easiness of the system, their preference to use it, completeness of patient information available on EMR, care providers interest for involvement at the design and implementation phase, and overall interest to use the system in future practice (Table 5).

\section{Results from the qualitative data}

The findings from the qualitative data explored overall views and detailed stories from the hospitals' management, EMR system administrators, and IT support personnel. These results were believed to reinforced the quantitative results and thus presented below. Further, a summary of general themes, sub-themes, and categories were presented (Table 6). 


\section{Suggested Barriers}

Low user acceptance, poor project management, poor infrustructure, lack of training \& follow-up

Low user acceptance, poor infrustructure, lack of training \& follow-up

Poor project management, poor infrustructure, lack of training \& follow up

Poor infrustructure, lack of training \& follow-up

Lack of Training \& follow-up

Poor ICT infrustructure

Poor project management

Low user acceptance

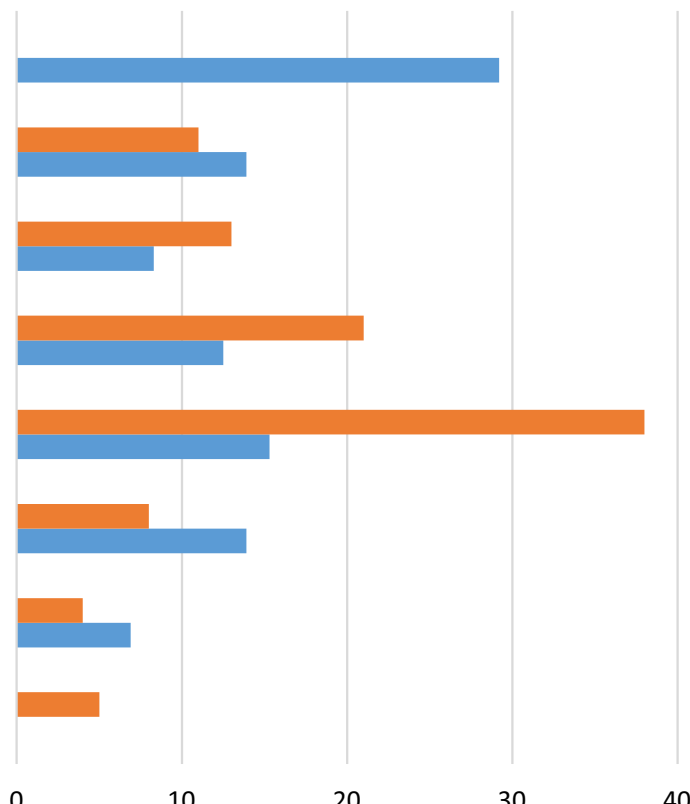

Ayder \% $\quad$ St. Paul's \%

Fig. 2 Suggested barriers to Implementation of EMR systems

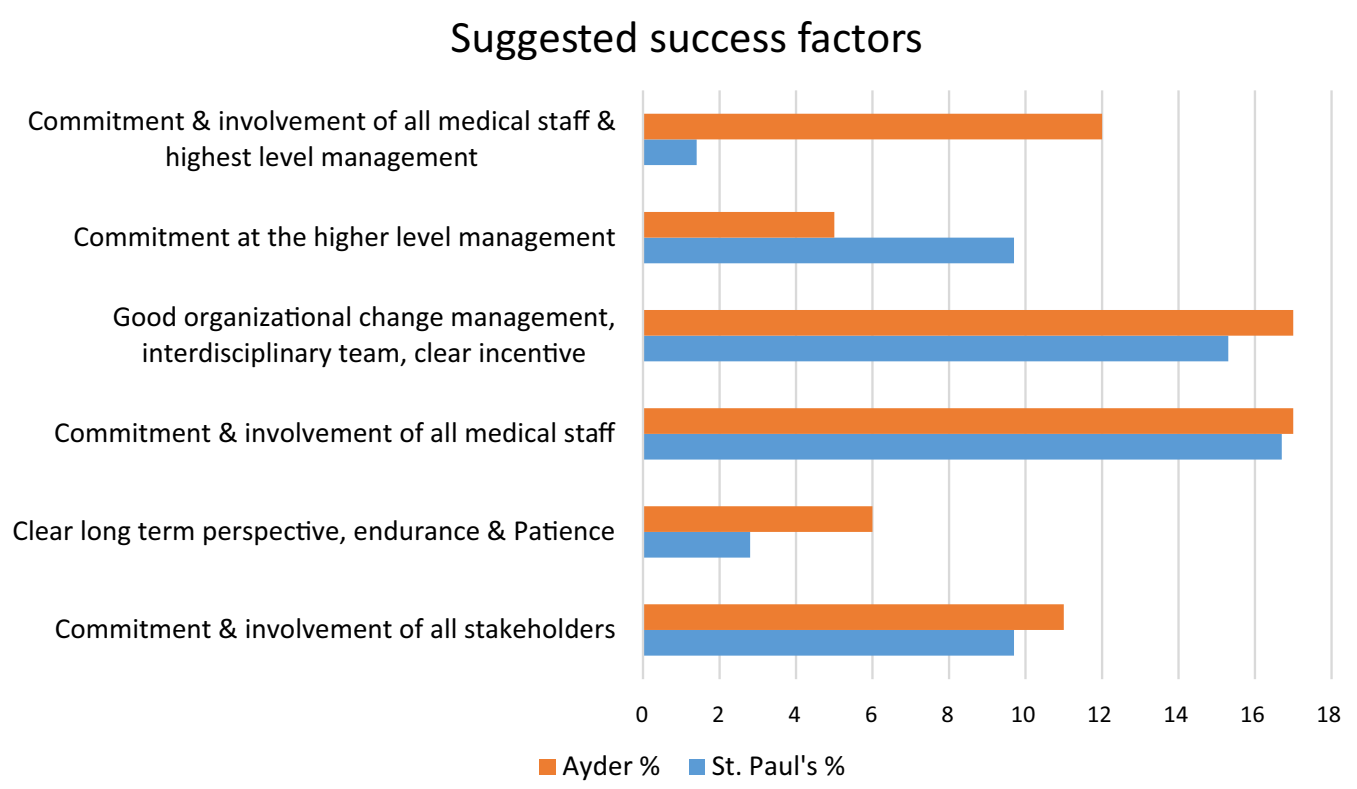

Fig. 3 Suggested factors for successful implementation of EMR systems

EMR system implementation objectives, deployment efforts and current status

The result showed the management of both hospitals were planned to replace paper-based record keeping with the electronic recording system by "implementing the SmartCare EMR system, which was determined 
Table 4 Views on EMR system contributions to Service improvement at Ayder Hospital

\begin{tabular}{llc}
\hline Items & \multicolumn{2}{c}{ Respondents Ins } \\
\cline { 2 - 3 } & \multicolumn{2}{c}{ Ayder Hospital } \\
\cline { 2 - 3 } & Freq & $\%$ \\
\hline Service turnaround time improved/ decreased by & using EMR system \\
Yes & 88 & $88.0 \%$ \\
No & 12 & $12.0 \%$ \\
By how much the time improved for the patient? & & \\
By 30 min & 39 & $39.0 \%$ \\
By $1 \mathrm{~h}$ & 36 & $36.0 \%$ \\
By 2 $\mathrm{h}$ & 8 & $8.0 \%$ \\
By More than 2 $\mathrm{h}$ & 7 & $7.0 \%$ \\
Not applicable & 10 & $10.0 \%$ \\
System down time affects clinical practice? & & \\
Very minimum effect & 12 & $12.0 \%$ \\
High effect & 45 & $45.0 \%$ \\
Serious effect & 35 & $35.0 \%$ \\
No effect at all & 8 & $8.0 \%$ \\
EMR system effect on patients waiting time? & & \\
Noted reduction of patient waiting time & 67 & $67.0 \%$ \\
Increased patient waiting time & 25 & $25.0 \%$ \\
No change & 8 & $8.0 \%$ \\
\hline
\end{tabular}

to improve the quality and efficiency and above all to reduce hospital costs" (Higher Hospital Management 001, 002, 006). As commented by interviewees, "this target was accomplished at Ayder, and the system is still well functioning. Currently, all medical services are becoming dependent on the system. We established an EMR committee, and in consultation with the representative from each department, we were able to maintain uninterruptable $24 \mathrm{~h}$ IT support" (Higher Hospital Management 001, 002).

At St. Paul's, the SmartCare EMR project was initiated in 2009, though the implementation was done in phases. As the respondent explained, "the initial phase started at the medical record room where the bulk of data encoding takes place. Then other clinical areas like the outpatient department followed. But unfortunately, the operation failed in the middle of 2010 Gregorian Calendar". The interviewee also added, "unsuccessful redeployment efforts made during the 2014 and 2017 Gregorian Calendar but the hospital was forced to practice predominantly with the traditional manual medical recording system - paper-based record-keeping" (Higher Hospital Management 006, 007, Sys Admin 008).
Table 5 Respondents perception and willingness to use EMR for future clinical practice

\begin{tabular}{|c|c|c|c|c|}
\hline \multirow[t]{3}{*}{ Items } & \multicolumn{4}{|c|}{ Respondents Institution } \\
\hline & \multicolumn{2}{|c|}{ St. Paul's } & \multicolumn{2}{|c|}{ Ayder Hospital } \\
\hline & Freq & $\%$ & Freq & $\%$ \\
\hline \multicolumn{5}{|c|}{ It would be easy for me to become skillful at using EMRs } \\
\hline Strongly disagree & 0 & $0.0 \%$ & 5 & $5.0 \%$ \\
\hline Disagree & 5 & $6.9 \%$ & 10 & $10.0 \%$ \\
\hline Don't know & 6 & $8.3 \%$ & 7 & $7.0 \%$ \\
\hline Agree & 40 & $55.6 \%$ & 55 & $55.0 \%$ \\
\hline Strongly agree & 21 & $29.2 \%$ & 23 & $23.0 \%$ \\
\hline \multicolumn{5}{|c|}{ I prefer EMR over paper charting } \\
\hline Strongly disagree & 1 & $1.4 \%$ & 9 & $9.0 \%$ \\
\hline Disagree & 7 & $9.7 \%$ & 9 & $9.0 \%$ \\
\hline Don't know & 3 & $4.2 \%$ & 12 & $12.0 \%$ \\
\hline Agree & 32 & $44.4 \%$ & 39 & $39.0 \%$ \\
\hline Strongly agree & 29 & $40.3 \%$ & 31 & $31.0 \%$ \\
\hline
\end{tabular}

Patient information obtained from EMR is more complete as compared to Paper medical record

$\begin{array}{llrlr}\text { Strongly disagree } & 0 & 0.0 \% & 6 & 6.0 \% \\ \text { Disagree } & 8 & 11.1 \% & 23 & 23.0 \% \\ \text { Don't know } & 11 & 15.3 \% & 11 & 11.0 \% \\ \text { Agree } & 28 & 38.9 \% & 39 & 39.0 \% \\ \text { Strongly agree } & 25 & 34.7 \% & 21 & 21.0 \%\end{array}$

My involvement at the system design and during the EMR implementation phase will make the EMR more useful to me

\begin{tabular}{llrlr} 
Strongly disagree & 0 & $0.0 \%$ & 4 & $4.0 \%$ \\
Disagree & 1 & $1.4 \%$ & 4 & $4.0 \%$ \\
Don't know & 5 & $6.9 \%$ & 9 & $9.0 \%$ \\
Agree & 42 & $58.3 \%$ & 65 & $65.0 \%$ \\
Strongly agree & 24 & $33.3 \%$ & 18 & $18.0 \%$ \\
would like to use EMRs in my work in future & & \\
Strongly disagree & 0 & $0.0 \%$ & 2 & $2.0 \%$ \\
Disagree & 1 & $1.4 \%$ & 4 & $4.0 \%$ \\
Don't know & 2 & $2.8 \%$ & 4 & $4.0 \%$ \\
Agree & 26 & $36.1 \%$ & 44 & $44.4 \%$ \\
Strongly agree & 43 & $59.7 \%$ & 45 & $45.5 \%$ \\
\hline
\end{tabular}

\section{ICT infrastructures and availability of technical support staff}

The result revealed ICT infrastructure at Ayder was in good standing. The interviewee replied that "during deployment of SmartCare EMR system, staffs from TUTAPE in collaboration with $\mathrm{FMoH}$ was responsible for providing all technical support. These were, installing and configuring the software, supplying equipment, taking system backup, training the IT staff and care providers, and follow-up of the project" (Sys Admin 003).

The respondent further explored that "later on, the establishment of an ICT infrastructure across the 
Table 6 Summary of qualitative data general themes, sub-themes and response categories

\begin{tabular}{|c|c|c|}
\hline Themes & Sub-themes & Response categories \\
\hline \multirow{4}{*}{ EMR implementation } & Deployment objective & Improve service quality, efficiency, decrease hospital cost \\
\hline & Current system status & Functioning at Ayder and failed at SPHMMC \\
\hline & & Dependency on the system at Ayder \\
\hline & & Using the manual system at SPHMMC \\
\hline \multirow[t]{2}{*}{ ICT infrastructure } & IT facilities and equipment & Network infrastructure \\
\hline & & Availability of equipment and facilities \\
\hline \multirow[t]{2}{*}{ IT support theme } & IT personnel & System administrators \\
\hline & & IT experts \\
\hline \multirow[t]{6}{*}{ Organization } & Management commitment & Priority in the plan \\
\hline & & Insure readiness of the hospitals \\
\hline & & Participation of care providers \\
\hline & & Availability of champions \\
\hline & & Top level management commitment \\
\hline & & Training and follow up \\
\hline \multirow[t]{16}{*}{ Barriers/impediments } & Human & Low staff awareness \\
\hline & & Resistance from the health workers \\
\hline & & Lack of skill \\
\hline & & Lack of training \\
\hline & & Work load on physicians \\
\hline & Finance & Non availability of fund \\
\hline & Organizational & Low level of management commitment \\
\hline & & Poor project management \\
\hline & & Change management \\
\hline & Technical & Lack of equipment \\
\hline & & Lack of standard/certified EMR system \\
\hline & & Poor ICT infrastructure, slow network connection \\
\hline & & Lack of technical expertise/IT \\
\hline & & Lack of system Interoperability and integration \\
\hline & & Lack of ease of use \\
\hline & & Data security/vulnerability \\
\hline \multirow[t]{13}{*}{ Success factors/facilitators } & Human & Management commitment \\
\hline & & Skilled manpower \\
\hline & & Change management \\
\hline & & Good project management, long term perspective \\
\hline & & Team sprit \\
\hline & & Training and follow up, motivation \\
\hline & & IT experts/system developers \\
\hline & & Availability of Champion \\
\hline & Finance & Availability of fund \\
\hline & & Incentives mechanism \\
\hline & Technical & Infrastructure, equipment \\
\hline & & Network speed \\
\hline & & Hardware and standard software availability \\
\hline
\end{tabular}

hospital and the university with IT facilities, equipment's and well-equipped data center, fortunately, bucked the SmartCare EMR implementation and contributed to have a sustainable system to the current date at Ayder"
(Sys Admin 003). Another major shortcoming reported by interviewees at both hospitals was associated with the wireless network connectivity; "The network predominantly is based on the wireless network connection which 
is prone to interference by other networks and sometimes obstructs the connection. It also lacks the required speed and has security problems" (Sys Admin 003, Sys Admin 008).

However, St. Paul's interviewee replied that "the hospital was lacking a well-developed IT infrastructure, facilities, equipment, and IT staff were almost nonexistent to take over the pilot work from TUTAPE which later resulted in the disappointment of users and the general collapse of the project" (Sys Admin 008, IT Support 009 and 010).

\section{Management commitment and future plan}

Regarding top management support and level of awareness of care providers, the result revealed that "top management were very committed, but at the beginning of the system deployment there was resistance to it from the physician's side while this improved after training and actual usage on the system" (Higher Hospital Management 002, Sys Admin 003).

The interviewee at St. Paul's revealed, "the management was committed to prior efforts, and there were recent initiations to implement a new EMR system" (Higher Hospital Management 006, Sys Admin 008). The interviewee further suggested that "hospital-wide readiness assessment, acquiring appropriate and certified system, improving ICT infrastructure, equipment and facilities need consideration" (Sys Admin 003, Sys Admin 008, IT Support 010).

\section{Barriers/impediments to implementation}

Findings from the senior management and IT experts' side at St. Paul's showed the existence of challenges that seriously impede former EMR implementation efforts. Quoted response from the interviewee presented as follows: "The challenges include intermittent connection with the network, poor network infrastructure, low staff awareness, low level of commitment from the top management, lack of integration and interoperability with other systems such as laboratory and PACS, IT support was almost nonexistent, there was no team/committee to coordinate or run the project, the software system lacks user-friendliness and there is resistance from the physicians not to use the system" (Sys Admin 008, IT Support 009 and 010).

Interview participants from Ayder hospital consented to the easiness of the software system but, they said that "initially, it was not designed in the way to meet the needs of the hospitals and end-users where it intended to serve. The system lacked interoperability as well as had maintenance issues. Fortunately, the developer at Ayder was initiated and worked on upgrading the system, making significant changes and major improvements to meet the requirements of end-users and today insured best performance system with the highest level of security" (Higher Hospital Management 002, Sys Admin 003, IT Support 004 and 005). "Wireless network connectivity, financing related to availing new computers and shortage of IT staff to respond to system-related emergencies at all corners of the hospital suggested still as obstacles at Ayder hospital" (Sys Admin 003, IT support 004).

\section{Success factors}

Interview participants from Ayder hospital identified several points for system success in their hospital. The response from the interviewees quoted as follows; "The sustainability of the EMR system depends mainly on the existence of 'individual champion' in this case, the commitment of the system administrator (developer) was crucial, and any system associated problems solved easily. Further, the ICT infrastructure and availability of other equipment and facilities were supportive of the successful implementation. The commitment of top management, concern, willingness, and involvement of medical staffs and availability of incentives for IT support staff contributed a lot" (Higher Hospital Management 001, Sys Admin 003, IT Support 005).

\section{Discussion}

An EMR system recognized in supporting a high-quality, integrated health care information system, which is independent of the place and time of health care delivery through information communication technology [19], is perceived to improve efficiency and increase the effectiveness of health care delivery $[6,10,15,20]$.

The two tertiary government hospitals were considered pioneers in introducing the EMR system at clinical settings and were assumed to transform the health care service with an improved flow of health information. The primary goals were achieving efficiency and effectiveness in the healthcare delivery system. Keeping structured information, minimizing medical errors, improving legibility of medical records, and in the meantime reducing hospital costs associated with the purchase of X-ray films, printing history sheets, lab orders, and other administrative expenses while supporting interoperability across information systems were aimed.

Deployment of the SmartCare EMR system took place in the 2009 Gregorian Calendar at Ayder hospital with support from TUTAPE, and FMoH was still functioning well. The initial version was upgraded and improved by the system developer of the hospital, and currently, Ayder has a better and dependable system to work on. While at St. Paul's though similar EMR systems implemented by TUTAPE at different times and technical support availed at the initial phase were comparable, all efforts were not 
successful and the researchers of this study examined the hospital predominantly working on the traditional paperbased patient recording system.

The literature identified training and follow-up as essential elements of EMR actualization and need consideration before any large-scale EMR implementation $[14,21,22]$. The finding from one study emphasized that an important pre-requisite for the implementation of an EMR system is to learn at least the basics of how to function on the software system [21]. Our study identified $75 \%$ of St. Paul's respondents had not attended previous EMR system-related training provided at the institution. This indicated the project failed at attaining one of the basic requirements to be fulfilled from the end-users' side.

Similar kinds of literature disclosed introduction of EMR in the health care delivery system had enhanced quality of care, improved communication, reduced error, increased safety, decreased care costs, and improved capability of conducting research $[6,15,23]$.

In a study conducted at a referral hospital in Kigali, Rwanda, which assessed health care consumers' perception of an EMR named OpenClinic, 88.2\% of participants perceived the quality of care had improved since the introduction of OpenClinic EMR [19]. Similarly, 80.6\% of the respondents supposed that the OpenClinic EMR had significantly changed the process of patient care positively, for instance, reduction in waiting time, improving the precision of record, improving safety and security of medical records [19]. One study concluded that, following the implementation of EMR in Kenya, patients spent less time waiting to see a consultant, and total time per visit at the health facilities was relatively shortened in duration [22].

In our study, the majority of participants confirmed similar findings as to the above researches. Service turnaround time is believed to be improved for $83.3 \%$ of St. Paul's and improved in real practice for $88 \%$ of Ayder hospital respondents. There is an expectation in reduction of patient waiting time for the majority of St. Paul's respondents (80.6\%), while 67\% of Ayder respondents attested actual reduction of patient waiting time using SmartCare EMR system for the last ten years.

The findings from this study assured, at Ayder hospital, the patient care process had changed significantly after the installation of the system. Quality of care had improved at Ayder for $84 \%$ of the respondents, implementation of SmartCare EMR had increased practice productivity, decreased the workload, and enhanced the efficiency of care providers. Concerning the safety of patient records, for sixty-three (87.5\%) of St. Paul's and eighty-six (86\%) of Ayder respondents, patient records available on the EMR system are safer and more secure when compared to the paper-based medical recording system.

Several studies demonstrated issues considered as obstacles to the implementation of an EMR system, were mainly associated with a shortage of human resources, hardware and software failure, user resistance, lack of computer literacy, lack of technical expertise, lack of awareness, lack of understanding stakeholders demand, and lack of appropriate ICT infrastructure with facilities and equipment $[10,12,15-18]$. Cost, privacy concerns, lack of uniform standards, resistance, lack of policy support, vendor support and maintenance, and lacking awareness, were mentioned as obstructing EMR system implementation $[9,18,19]$. Further, as the literature explored, EMR implementation projects were inhibited fundamentally, with issues related to technical support, financing, procuring sufficient logistics, health professionals' beliefs and attitudes, electronic data exchange standards, and interoperability of the system [22, 24, 25].

The finding from qualitative and quantitative data of this study confirmed low user acceptance, poor project leadership, poor network connectivity, low staff awareness, lack of training and follow-up, and low level of commitment from the top management were the barriers to the system implementation and accounted for the failure of deployment and redeployment efforts in 2009, 2014 and 2017 Gregorian Calendar. Similarly, unfriendly user interface, lack of integration and interoperability with another system, unsatisfactory IT support, unavailability of a robust team to play the leadership role, and other hardware/software related issues were considered as an obstruction. Appropriate supports which were required for implementation and meaningful use of the EMR system was non-existent at St. Paul's hospitals, did not have funding, there were no appropriate incentives for IT staff as well as end-users.

On the other hand, as some studies revealed, for successful EMR implementation; skilled IT personnel, training, infrastructures, change management, reliable system, effective project management, motivation, faster network, reliable data handling methods, and uninterrupted power supply, have vital importance [10, 24, 26, 27]. Our study revealed, beyond a well-established ICT infrastructure with the state-of-the-art technology data center, the commitment of all stakeholders and top management, involvement of care providers at the system design, testing, and implementation phase, and clear long-term perspective would result in successful implementation.

Another study identified some difficulties which are associated with wireless network connection stating that: it is prone to interference by other networks and wireless-enabled devices, objects such as walls can obstruct connection, it lacks the required data transmission speed, 
it is less secure, and ultimately these all compromise performance and quality of the network connection [28]. Similarly, in our study, the findings from the qualitative data explored problems associated with the existing network infrastructure at both hospitals, which is predominantly based on a wireless network and reported as it is a source of discomfort for end users. The result also disclosed that the Ayder hospital administration has started to address wired network connectivity problems at all places of the hospital, to ensure the sustenance of the system.

As the findings from the qualitative as well as quantitative study attested, at St. Paul's hospital, the scenario was still unattractive for hospital-wide technology application. The management seems confident and eager to adopting innovative health information technologies to support clinical activities like the EMR. But the findings showed flourishing poor organizational ICT infrastructure, shortage of IT staff, and unavailability of standard software meeting the health information technology requirement that was considered as impeding earlier EMR deployments, hopefully, obstruct any future initiation efforts.

In general, the findings from this study attested how health information technology, particularly EMR, is changing the landscape in which health care service is being delivered locally. We can draw a lesson from this experience at Ayder that confirms a single health information technology application saved hospital costs of around 75,000 USD per year, which was expended only for the purchase of X-ray film for producing radiographic images. The existence of favorable ground such as well-equipped ICT infrastructure, top management commitment, uninterrupted technical support, technology-seeking behavior among care providers is also valuable lessons for St. Paul's or other similar health care organizations at similar system implementation projects.

\section{Limitation of the study}

The findings of this study have to be seen in light of some limitations. We understand that the sample size of the qualitative part is small and limited. Though we applied the purposive sampling technique and ensured the trustworthiness of the findings, this may prevent them from being extrapolated. We suggested further research with a large sample.

\section{Conclusion and recommendation}

Implementing and practicing an EMR system at any tier of the health care system has been shown to increase medical practices' productivity and quality of care. In resource-limited countries like Ethiopia, considering EMR for clinical care is no more a luxury. It is just being a requirement for providing modern standard care for patients and their families.

This research has studied the adoption and implementation of EMR systems at two tertiary care hospitals in Ethiopia-St. Paul's and Ayder. The implementation outcomes are significantly different with achieving the initial objectives and maintaining a sustainable system where successful progress was observable at Ayder hospital.

Thus, primarily, assessing institutional and health professionals' readiness, selecting and acquiring the best appropriate and certified EMR system meeting well-identified requirements of the local health care system, needs thoughtful attention. Adopting a sustainable EMR system at the hospital level further entails providing adequate logistics requirements such as equipment and facilities, reliable network connection, training and follow-up, power, and data backups. Besides, an IT and health care team, stakeholders' engagement, top management commitment, and establishing ways and means for rewarding staff is overriding.

\section{Abbreviations}

BLH: Black Lion Hospital; CDC: Centers for Disease Control; EHR: Electronic Health Record; EMR: Electronic Medical Record; FMoH: Federal Ministry of Health; IT: Information Technology; ICT: Information and Communication Technology; OPD: Out Patient Department; UPS: Uninterruptable Power Supply.

\section{Supplementary Information}

The online version contains supplementary material available at https://doi. org/10.1186/s12911-021-01670-z.

Additional file 1 Title of data: Questionnaire and Interview guide for implementation challenges and perception of care providers on EMR at St. Paul's and Ayder Hospitals, Ethiopia. Description of Data: A structured and pre-validated questionnaire which contains sections on Socio-Demographics; Knowledge, Perceived Benefits and Usefulness; and Perception and Willingness; whereas a pre-distributed interview guide employed to interview the key informants assuming to get more detailed information in support of findings from the questionnaire

\section{Acknowledgements}

The authors would like to acknowledge study participants at both hospitals for their willingness to take time out of their busy schedules to participate in this study. We are also thankful to those data collectors working at Ayder teaching hospital, Mekele, Ethiopia, for their support in the survey. Our gratitude would also go to Lenny Rhine (Ph. D), Florida, USA, for his unreserved contribution in editing the draft manuscript.

\section{Authors' contributions}

$A B$ is $P I$ of the study. $A B$ and $D M$ conceived the original idea and designed the study. AB, DM, and TA supervised the data collection. AB and DM analyzed and interpreted the data and prepared the first manuscript draft. BAs, BAb and TM critically reviewed the paper and added intellectual content. All authors commented, reviewed and approved the final manuscript.

Funding

Partial expenses related to data collection at Ayder hospital was covered by Center of Excellence in Reproductive Health, St. Paul's Hospital Millennium Medical College. Funder has no role in the study design, data collection and in writing the manuscript. 


\section{Availability of data and materials}

The data that support the findings of this study will be available from the corresponding author upon reasonable request in the form of statistical package for social sciences (SPSS).

\section{Declarations}

\section{Ethics approval and consent to participate}

Ethical approval was obtained from St. Paul's Hospital Millennium Medical College Institutional Review Board (IRB). Informed verbal and written consent from each individual respondent was obtained.

\section{Consent for publication}

Not applicable.

\section{Competing interests}

The authors declare that they have no competing interests.

\section{Author details}

'Library and Info Service Directorate, St. Paul's Hospital Millennium Medical College, PO Box 1271, Addis Ababa, Ethiopia. ${ }^{2}$ ICT Directorate, St. Paul's Hospital Millennium Medical College, Addis Ababa, Ethiopia. ${ }^{3}$ Medical Education Unit, St. Paul's Hospital Millennium Medical College, Addis Ababa, Ethiopia.

${ }^{4}$ Health Informatics and Healthcare Innovation Department, School of Public Health, College of Health Sciences, Mekele University, Mekele, Ethiopia.

Received: 3 June 2020 Accepted: 26 October 2021

Published online: 02 November 2021

\section{References}

1. Ross DS, Venkatesh R. Role of hospital information systems in improving healthcare quality in hospitals. Indian J Sci Technol. 2016. https://doi.org/ 10.17485/ijst/2016/v9i26/92686.

2. Alotaibi YK, Federico F. The impact of health information technology on patient safety. Saudi Med J. 2017;38(12):1173-80. https://doi.org/10. 15537/smj.2017.12.20631

3. Luna D, Almerares A, Mayan JC 3rd, Gonzalez-Bernaldo-de-Quiros F, Otero C. Health informatics in developing countries: going beyond pilot practices to sustainable implementations: a review of the current challenges. Healthc Inform Res. 2014;20(1):3-10.

4. WHO. Management of patient information: trends and challenges in Member States: based on the findings of the second global survey on eHealth. Global Observatory for eHealth Series, v. 6. Geneva: World Health Organization; 2012.

5. Rihab H, Kirsten V, Michele C. Progress and challenges in the implementation of electronic medical records in Saudi Arabia: a systematic review. Health Inform Int J. 2014;3(2):1-14.

6. Shahmoradi L, Darrudi A, Arji G, Nejad AF. Electronic health record implementation: a SWOT analysis. Acta Med Iran. 2017;55(10):642-9.

7. Ahmadi H, Nilashi M, Almaee A, Soltani M, Zare M, Sangar AB, et al. Multilevel model for the adoption of hospital information system: a case on Malaysia. J Soft Comput Decis Support Syst. 2016;3(1):61-74.

8. Ohuabunwa EC, Sun J, Jubanyik KJ, Wallis LA. Electronic medical records in low to middle income countries: the case of Khayelitsha Hospital, South Africa. Afr J Emerg Med. 2016;6:38-43.

9. Mohamadali Noor A, Zahari NA. The organization factors as barrier for sustainable health information systems (HIS): a review. 4th information systems international conference 2017, ISICO 2017, 6-8 November 2017, Bali, Indonesia. Procedia Comput Sci. 2017;124:354-61.

10. Msiska KEM, Kumitawal A, Kumwenda B. Factors affecting the utilization of electronic medical records system in Malawian central hospitals. Malawi Med J. 2017;29(3):247-53.
11. Raut A, Yarbrough C, Singh V, Gauchan B, Citrin D, Verma V, et al. Design and implementation of an affordable, public sector electronic medical record in rural Nepal. J Innov Health Inform. 2018;24(2):862.

12. Joukes E, de Keizer NF, de Bruijne MC, Abu-Hanna A, Cornet R. Impact of electronic versus paper-based recording before EHR implementation on health care professionals' perceptions of EHR use, data quality, and data reuse. Appl Clin Inform. 2019;10:199-209.

13. King J, Patel V, Jamoom EW, Furukawa MF. Clinical benefits of electronic health record use: national findings, part II. Health Serv Res. 2014;49:1.

14. Joukes E, Cornet R, Abu-Hanna A, Bruijne-De M, Keizer-De N. End-user expectations during an electronic health record implementation: a case study in two academic hospitals. In: Cornet R, Stoicu-Tiradar L, Horbst A, editors. Digital healthcare empowering europeans. European Federation for Medical Informatics (EFMI). Geneva: IOS; 2015. p. 501-5.

15. Jawhari B, Ludwick D, Keenan L, Zakus D, Hayward R. Benefits and challenges of EMR implementations in low resource settings: a state-of-theart review. BMC Med Inform Decis Mak. 2016;16:116. https://doi.org/10. 1186/s12911-016-0354-8.

16. Gyamfi A, Mensah Kofi A, Oduro G. Barriers and facilitators to electronic medical records usage in the emergency centre at Komfo Anokye Teaching Hospital, Kumasi-Ghana. Afr J Emerg Med. 2017;7:177-82.

17. Khalifa M. Barriers to health information systems and electronic medical records implementation: a field study of saudi arabian hospitals. Procedia Comput Sci. 2013;21:335-42.

18. Jaillah MG, Almarie B, Kristelle SM, Adrian G. Barriers to electronic health record system implementation and information systems resources: a structured review. Procedia Comput Sci. 2017;124:544-51.

19. Peace U, Kato N, Assouman N, Anne K, Moses I, Julienne M, et al. Health care consumer's perception of the electronic medical record (EMR) system within a referral hospital in Kigali, Rwanda. Rwanda J Ser F Med Health Sci. 2017:4:1.

20. Fritz F, Tilahun B, Dugas M. Success criteria for electronic medical record implementations in low-resource settings: a systematic review. J Am Med Inform Assoc. 2015;22(2):479-88.

21. Pantaleoni JL, Stevens LA, Mailes ES, Goad BA, Longhurst CA. Successful physician training program for large scale EMR implementation. Appl Clin Inf. 2015;6:80-95.

22. Muinga N, Magare S, Monda J, Kamau O, Houston S, Fraser H, et al. Implementing an open source electronic health record system in Kenyan health care facilities: case study. JMIR Med Inform. 2018. https://doi.org/ 10.2196/medinform.8403

23. Tierney WM, Sidle JE, Diero LO, et al. Assessing the impact of a primary care electronic medical record system in three Kenyan rural health centers. J Am Med Inform Assoc. 2015. https://doi.org/10.1093/jamia/ocv074.

24. Gagnon MP, Simonyan D, Ghandour EK, Godin G, Labrecque M, Ouimet $M$, et al. Factors influencing electronic health record adoption by physicians: a multilevel analysis. Int J Inform Manag. 2016;36:258-70.

25. Ologeanu-Taddei R, Morquin D, Vitari C. Perceptions of an electronic medical record (EMR): lessons from a French longitudinal survey. Procedia Comput Sci. 2016;100:574-9.

26. Sidek YH, Martins JT. Perceived critical success factors of electronic health record system implementation in a dental clinic context: an organizational management perspective. Int J Med Inform. 2017;107:88-100.

27. Schopfi TR, Nedrebo B, Hufthammer KO, Daphu IK, Laerum H. How well is the electronic health record supporting the clinical tasks of hospital physicians? A survey of physicians at three Norwegian hospitals. BMC Health Serv Res. 2019;19:934.

28. Tiwari P, Saxena VP, Mishra RG, Bhavsar D. Wireless sensor networks: introduction, advantages, applications and research challenges. HCTL Open Int J Technol Innov Res. 2015:14:1-11.

\section{Publisher's Note}

Springer Nature remains neutral with regard to jurisdictional claims in published maps and institutional affiliations. 